\title{
A simplified method for the quantitative determination of urinary coproporphyrin in lead workers
}

\author{
JOAN SOULSBY AND R. L. SMITH \\ Department of Pathology, Chase Farm Hospital, Enfield, Middlesex EN2 8JL
}

\begin{abstract}
Soulsby, Joan and Smith, R. L. (1974). British Journal of Industrial Medicine, 31, 72-74. A simplified method of estimating urinary coproporphyrin is described, based on the method of Rimington (1971). Coproporphyrin and coproporphyrinogen are extracted into ether from acidified urine; the ether is then shaken with a solution of iodine in hydrochloric acid to oxidize any coproporphyrinogen to coproporphyrin and to extract the coproporphyrin. The solution is examined spectrophotometrically for coproporphyrin at the peak of the Soret band and at wavelengths on either side to correct for any impurities present.

A comparison with the method of Rimington (1971) in 94 urine samples with coproporphyrin levels up to $2.5 \mathrm{mg} / \mathrm{l}$ showed good agreement. Correlation coefficient $(r)=+0.986$. One hundred estimations can be carried out in five hours.
\end{abstract}

The estimation of urinary coproporphyrin is used in the assessment of inorganic lead absorption (Lane et al., 1968). Waldron (1971) found it to be a suitable screening test to monitor a lead hazard. The quantitative method of Rimington (1971) is satisfactory but time consuming, and we have found semiquantitative tests, based on the red fluorescence of coproporphyrin, difficult to interpret. The following procedure was therefore devised.

\section{Method}

\section{Reagents}

Glacial acetic acid. Anaesthetic ether. Hydrochloric acid (approximately $5 \mathrm{~g} / 100 \mathrm{ml}$ ) $120 \mathrm{ml}$ concentrated acid diluted to one litre with distilled water. $1 \%$ iodine in ethanol, stored at $4^{\circ}$ in the dark. Hydrochloric acid-iodine solution prepared freshly each day by mixing $1 \mathrm{ml} 1 \%$ iodine and $200 \mathrm{ml} 5 \%$ hydrochloric acid.

\section{Procedure}

Place $2 \mathrm{ml}$ of mixed urine in a glass-stoppered tube $(125 \mathrm{~mm}$ $\times 15 \mathrm{~mm})$ and add acetic acid $(0.2 \mathrm{ml})$ and anaesthetic ether $(5 \mathrm{ml})$. Shake for 15 seconds and then allow the phases to separate. Remove the lower aqueous layer; add hydrochloric acid-iodine solution $(5 \mathrm{ml})$ to the ether layer and shake for 15 seconds. Allow the phases to separate, remove the upper layer of ether, and place the unstoppered tube in a water bath at $37^{\circ}$ for 5 minutes. Re-stopper the tube and shake. Measure the optical density in a spectrophotometer, using a $1 \mathrm{~cm}$ cuvette, at wavelengths of 380 and $430 \mathrm{~nm}$ and at the peak of the Soret band (about $401 \mathrm{~nm})$.

\section{Calculation of results}

If Dmax = optical density at peak of Soret band

D $430=$ optical density at $430 \mathrm{~nm}$

D $380=$ optical density at $380 \mathrm{~nm}$

Then

$[2 \mathrm{Dmax}-(\mathrm{D} 430+\mathrm{D} 380)] \times 2.093 \times 1.064=\mathrm{mg}$ coproporphyrin/litre.

\section{Comparison with the method of Rimington (1971)}

One hundred random urine samples were collected from lead workers over a period of several months. Coproporphyrin estimations were carried out by the method of Rimington (1971) and by the simplified 
method. All estimations were carried out in duplicate and both methods were undertaken on the same day to avoid differences due to deterioration of the specimen with time and exposure to light.

Ninety-four of the samples had coproporphyrin levels up to $2.5 \mathrm{mg} / 1$. The results from these samples are shown in the Figure. The values for the remaining six urines are shown in the Table. In all cases the values shown are the means of duplicate estimations.

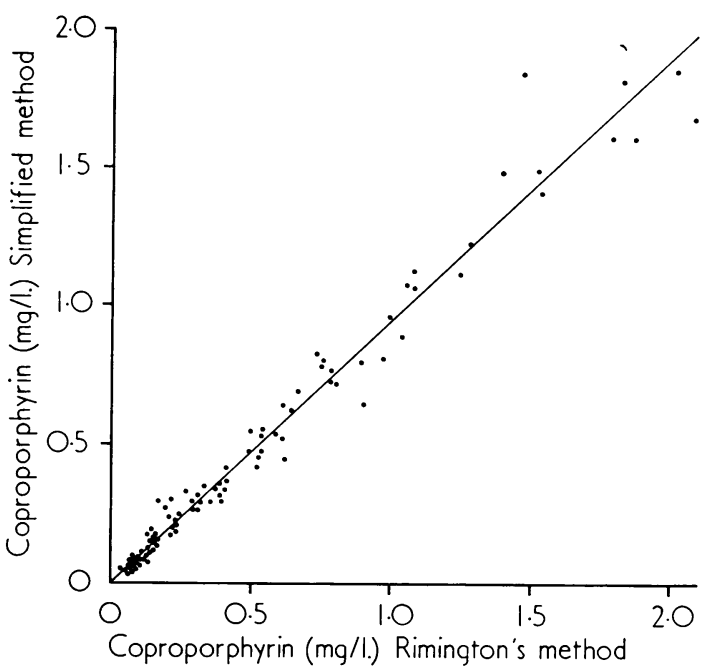

FIGURE Comparison of urine coproporphyrin estimated by the method of Rimington (1971) $(X)$ and the simplified method $(Y)$. The regression line of $Y$ on $X$ is given $(Y=0.939 X), \mathrm{n}=94, \mathrm{r}=+0.986$.

The correction factor of 1.064 has not been applied to the values for the simplified method.

\section{TABLE}

URINE COPROPORPHYRIN ESTIMATION BY THE METHOD of Rimington (1971) aNd the Simplified Method (VALUES NOT SHOWN IN Figure)

\begin{tabular}{|c|c|c|}
\hline \multirow[b]{2}{*}{ Diagnosis } & \multicolumn{2}{|c|}{ Urine coproporphyrin $(\mathrm{mg} / \mathrm{l})$} \\
\hline & $\begin{array}{l}\text { Rimington's } \\
\text { method }\end{array}$ & $\begin{array}{l}\text { Simplified } \\
\text { method }\end{array}$ \\
\hline $\begin{array}{l}\text { Lead worker } \\
, ", \\
, ", \\
, ", \\
\text { ", ", } \\
\text { Acute intermittent } \\
\text { porphyria } \\
\text { Acute intermittent } \\
\text { porphyria }\end{array}$ & $\begin{array}{l}3 \cdot 269 \\
3 \cdot 576 \\
3 \cdot 677 \\
4 \cdot 377 \\
6 \cdot 391 \\
7 \cdot 075 \\
\\
1 \cdot 010 \\
\\
0 \cdot 310\end{array}$ & $\begin{array}{l}2 \cdot 753 \\
2 \cdot 731 \\
3 \cdot 250 \\
3 \cdot 491 \\
5 \cdot 236 \\
5 \cdot 055 \\
1 \cdot 113 \\
\\
1 \cdot 447\end{array}$ \\
\hline
\end{tabular}

The correction factor of 1.064 has not been applied to the values for the simplified method.
The results show two distinctive features. First, with urine coproporphyrin levels over $2.5 \mathrm{mg} / \mathrm{l}$, the simplified method gave significantly lower answers than Rimington's method, giving a pronounced curve in the overall pattern of the results. For clinical use the exact value of these high concentrations is not very important, so for the purposes of fitting a suitable equation these high values were ignored.

Secondly, the variance of the observations increases with increase of the concentration of coproporphyrin. Consequently, a weighted least squares analysis was used to fit a straight line through the origin.

The regression details are as follows:

Regression equation $\mathrm{Y}=0.939 \mathrm{X}$

Coefficient of correlation $=0.986$

No. of observations $=94$

Standard error of slope of regression line $=0.014$

Standard error about the line $=\sqrt{X} / 10$

The slope of the regression line (0.939) differs significantly from $1(P<0.05)$.

The variance between duplicates for both methods increases with the concentration of coproporphyrin in the samples. For the simplified method the variance between duplicates (over the range $0-2.5 \mathrm{mg} / \mathrm{l}$ ) was approximately equal to $\mathrm{X} / 1000$ which was about half that for the Rimington method.

\section{Discussion}

The main differences between this method and that of Rimington (1971) are as follows. Single extractions are used instead of repeated extractions. This would account for the fact that the simplified method gave, in general, lower results than Rimington's method. To allow for this it is suggested that, in calculating the results, the factor of 2.093 used by Rimington is multiplied by 1.064 , the reciprocal of the factor obtained in the regression equation.

The sodium acetate wash was omitted, for in no sample during the execution of Rimington's method did the acetate wash show any red fluorescence under ultraviolet light. The iodine and hydrochloric acid were combined into one reagent. The excess iodine passed into the ether layer and was removed. Warming the acid solution to $37^{\circ} \mathrm{C}$ removed dissolved ether. Without this step, bubbles sometimes formed during the photometric readings.

Optical density readings for this comparative investigation were made manually. A more rapid method is to scan the acid extract over the range $380-430 \mathrm{~nm}$ in a recording spectrophotometer. The height of the peak above the baseline can be measured with a scale calibrated directly in milligrammes coproporphyrin per litre. Using this method, 100 estimations can easily be carried out by a single worker in one day.

Rimington's method and the simplified method were applied to two urine specimens from two cases 
of acute intermittent porphyria. The results are shown in the Table. These results throw doubt on the reliability of the simplified method in cases of porphyria, although the second urine had been stored for six weeks before examination.

We should like to thank for their help and advice Dr. M. H. P. Sayers of the Medical Services Division, Department of Employment, Mr. H. Howson of the Statistics Division, Department of Employment, and Mr. H. S.
Norwich of the Management Services Division, North East Metropolitan Regional Hospital Board.

\section{References}

Lane, R. E. and 17 others. (1968). Diagnosis of inorganic lead poisoning: a statement. British MedicalJournal, 4, 501.

Rimington, C. (1971). Quantitative determination of porphobilinogen and porphyrins in urine and faeces and erythrocytes. Association of Clinical Pathologists Broadsheet No. 70.

Waldron, H. A. (1971). Correlation between some parameters of lead absorption and lead intoxication. British Journal of Industrial Medicine, 28, 195-199.

\section{The October (1973) Issue}

Assessment of man's thermal comfort in practice $P$. O. FANGER

Comfort studies of rail passengers J. F. Nicol, C. Doré, J. S. Weiner, D. E. Lee, S. P. Prestidge, AND M. J. ANDREWS

Effect of treatment on physiological responses to exercise in East African industrial workers with iron deficiency anaemia C. T. M. Davies and J. P. M. VAN HaARen

Interindividual differences in circadian fatigue patterns of shift workers O. ÖsTBERG

Electroencephalographic studies on petrol intoxication: comparison between nonleaded and leaded white petrol K. SAITO

Comparative study of effect of inorganic lead and cadmium on blood $\delta$-aminolevulinate dehydratase in man R. R. LAUWERYS, J.-P. BUChet, AND H. A. Roels

A comparison of conventional and grid techniques for chest radiography in field surveys J. S. WASHINGTON, J. A. Dick, M. Jacobsen, AND W. M. Prentice

Respiratory response in simultaneous exposure to flax and hemp dust E. ŽUšKIN AND F. VALIĆ

Pharmacological prevention of acute ventilatory capacity reduction in flax dust exposure F. VALIĆ AND E. ŽUŠKIN

\section{Symptomatology of chronic brucellosis D. G. McDevitT}

A new method for the determination of mandelic acid excretion at low level styrene exposure A. SLOB

Notes and miscellanea

Accuracy and precision of two methods of blood lead estimation A. J. Fox AND M. H. P. SAYERS

Treatment of rapidly progressive rheumatoid pneumoconiosis $\quad$ D. DAVIES

Permanent Commission and International Association on Occupational Health: Sub-committee on Absenteeism: Draft recommendations

Book reviews

Information section

Index

A number of copies are still available and may be obtained from the Publishing Manager, British Medical Association, Tavistock Square, London WC1H 9JR, price $£ 1.25$ ( $£ 1.50$ in countries overseas; U.S.A. \$3.60). 